\title{
Hypocretins Regulate the Anxiogenic-Like Effects of Nicotine and Induce Reinstatement of Nicotine-Seeking Behavior
}

\author{
Ainhoa Plaza-Zabala, ${ }^{1}$ Elena Martín-García, ${ }^{1}$ Luis de Lecea, ${ }^{2}$ Rafael Maldonado, ${ }^{1}$ and Fernando Berrendero ${ }^{1}$ \\ ${ }^{1}$ Laboratory of Neuropharmacology, Department of Experimental and Health Sciences, Pompeu Fabra University, 08003 Barcelona, Spain, \\ and ${ }^{2}$ Department of Psychiatry and Behavioral Sciences, Stanford University, Palo Alto, California 94304
}

Emerging evidence suggests that the hypocretinergic system is involved in addictive behavior. In this study, we investigated the role of these hypothalamic neuropeptides in anxiety-like responses of nicotine and stress-induced reinstatement of nicotine-seeking behavior. Acute nicotine $(0.8 \mathrm{mg} / \mathrm{kg}$, s.c.) induced anxiogenic-like effects in the elevated plus-maze and activated the paraventricular nucleus of the hypothalamus (PVN) as revealed by c-Fos expression. Pretreatment with the hypocretin receptor 1 (Hcrtr-1) antagonist SB334867 or preprohypocretin gene deletion blocked both nicotine effects. In the PVN, SB334867 also prevented the activation of corticotrophin releasing factor (CRF) and arginine-vasopressin (AVP) neurons, which expressed Hcrtr-1. In addition, an increase of the percentage of c-Fos-positive hypocretin cells in the perifornical and dorsomedial hypothalamic (PFA/DMH) areas was found after nicotine ( $0.8 \mathrm{mg} / \mathrm{kg}$, s.c.) administration. Intracerebroventricular infusion of hypocretin-1 (Hcrt-1) $(0.75 \mathrm{nmol} / 1 \mu \mathrm{l})$ or footshock stress reinstated a previously extinguished nicotine-seeking behavior. The effects of Hcrt-1 were blocked by SB334867, but not by the CRF1 receptor antagonist antalarmin. Moreover, SB334867 did not block CRF-dependent footshock-induced reinstatement of nicotine-seeking while antalarmin was effective in preventing this nicotine motivational response. Therefore, the Hcrt system interacts with CRF and AVP neurons in the PVN and modulates the anxiogenic-like effects of nicotine whereas Hcrt and CRF play a different role in the reinstatement of nicotineseeking. Indeed, Hcrt-1 reinstates nicotine-seeking through a mechanism independent of CRF activation whereas CRF mediates the reinstatement induced by stress.

\section{Introduction}

Tobacco smoking is a major public health problem worldwide characterized by loss of control over tobacco consumption despite the harmful effects, the appearance of withdrawal symptoms upon smoking cessation, and relapse after periods of abstinence (McLellan et al., 2000). Once cessation of use has been established, preventing relapse is the main objective of the treatment. Stress has been shown to increase vulnerability and cause relapse to nicotine-seeking behavior in humans (Cohen and Lichtenstein, 1990), and animal models (Bilkei-Gorzo et al., 2008; Martín-García et al., 2009). Human and animal studies have also revealed that nicotine modifies anxiety-like behavior, which could participate in its addictive properties. Smokers report that tobacco consumption decreases anxiety and alleviates

Received Nov. 18, 2009; revised Dec. 14, 2009; accepted Dec. 19, 2009.

This work was supported by the Instituto de Salud Carlos III Grants PI070559 (FIS) and RD06/001/001 (RTARETICS), by the Spanish Ministry of Science and Technology (Consolider-C, SAF2007-64062), by the European Commission (IP LSHM-CT-2004-05166, GENADDICT; and STREP LHSM-CT-2007-037669, PHECOMP), by the Catalan Institution for Research and Advanced Studies (ICREA Academia program), and by Generalitat de Catalunya (2009SGR00731). L.d.L. is supported by grants from the National Institute on Drug Abuse, National Alliance for Research on Schizophrenia and Depression, and Defense Advanced Research Projects Agency. E.M.-G. was supported by a postdoctoral fellowship from the Spanish Instituto de Salud Carlos III. A.P.-Z. is a recipient of a predoctoral fellowship from the Spanish Ministry of Education. We thank R. Cabrera, M. Linares, T. Hansson, and C. FernándezAvilés for invaluable technical assistance, and T. Sakurai and M. Yanagisawa for generously providing preprohypocretin knock-out mice.

Correspondence should be addressed to Fernando Berrendero at the above address. E-mail: fernando. berrendero@upf.edu.

D0I:10.1523/JNEUROSCI.5724-09.2010

Copyright $\odot 2010$ the authors $\quad 0270-6474 / 10 / 302300-11 \$ 15.00 / 0$ stress (Pomerleau, 1986; Kassel and Unrod, 2000), although other studies have reported that nicotine can also increase levels of anxiety (Newhouse et al., 1990; Foulds et al., 1997). In agreement with the possible anxiolytic-like effects of nicotine, smokers display higher scores in anxiety-related tests than nonsmokers (Parrott, 1995). According to human studies, several reports have shown that nicotine induces anxiogenic- or anxiolytic-like responses in rodents depending on the dose, the route of administration, the genetic strain and the baseline anxiety level (File et al., 2000; Balerio et al., 2005). The neurobiological mechanisms underlying the effects of nicotine on anxiety and stress remain to be clarified.

Hypocretin-1 and 2 (Hcrt-1 and Hcrt-2), also known as orexin $\mathrm{A}$ and $\mathrm{B}$, are neuropeptides produced exclusively in neurons of the lateral hypothalamus and contiguous perifornical area (de Lecea et al., 1998; Sakurai et al., 1998) that project widely through the brain (Peyron et al., 1998). These peptides produce their physiological effects acting on two G-protein coupled receptors, hypocretin receptors 1 and 2 (Hcrtr-1 and Hcrtr-2) (de Lecea et al., 1998; Sakurai et al., 1998). Hcrt-1 binds to both receptors with similar affinity, whereas Hcrt-2 binds to Hcrtr-2 with tenfold greater affinity than to Hcrtr-1. The hypocretinergic system was initially involved in the regulation of food intake, energy metabolism and the maintenance of arousal (Harris and Aston-Jones, 2006). However, recent studies have demonstrated that hypocretins take part in reward processing and addiction (Aston-Jones et al., 2009; Sharf et al., 2009). Thus, Hcrt transmission participates in morphine (Narita et al., 
2006), ethanol (Lawrence et al., 2006) and nicotine (Hollander et al., 2008) rewarding properties. In addition, Hcrt-containing neurons are sensitive and can also regulate the activity of arousalpromoting transmitters, including the corticotrophin releasing factor (CRF), a peptide involved in stress responses (WinskySommerer et al., 2004). The increased activity of Hcrts leads to a state of hyperarousal that could contribute to the vulnerability to relapse for drug seeking (de Lecea et al., 2006). In agreement, Hcrtr-1 blockade attenuates stress-induced reinstatement of extinguished cocaine (Boutrel et al., 2005) and alcohol (Richards et al., 2008) seeking.

This study was undertaken to investigate whether the Hcrt system regulates the behavioral and biochemical processes underlying nicotine-induced anxiety-like responses and the reinstatement of nicotine-seeking behavior. The specific involvement of the CRF system in the effects of Hcrt transmission on these two behavioral responses related to nicotine addiction was also evaluated.

\section{Materials and Methods}

Animals

Experiments were performed in male C57BL/6J mice (Charles River) and in male preprohypocretin knock-out (KO) and their wild-type C57BL/6J mice (8-10 weeks old). Generation of mice with a deletion of the preprohypocretin gene has been previously described (Chemelli et al., 1999). These mice do not produce either of the Hcrt-1 or Hcrt-2 peptides and have been extensively characterized at the behavioral level. Thus, KO mice display fragmented sleep and behavioral arrests reminiscent of cataplexy during the dark period, but otherwise normal sleep homeostasis (Mochizuki et al., 2004). Under ad libitum conditions, feeding and drinking patterns are also normal. Preprohypocretin KO mice were backcrossed for 9 generations into C57BL/6J, and genotyped as described previously (Chemelli et al., 1999). Mice were housed five per cage in a temperature $\left(21 \pm 1^{\circ} \mathrm{C}\right)$ - and humidity $(55 \pm 10 \%)$-controlled room. For the reinstatement study, mice were single housed and exposed to a reversed $12 \mathrm{~h}$ light/dark cycle (lights off 8:00 A.M.) and the experiments took place during the dark phase. These mice were habituated to the reversed cycle conditions for 1 week before starting the nicotine selfadministration sessions. For the other experiments, mice were exposed to a normal cycle (lights on 8:00 A.M.) and the experiments took place in the light phase. Food and water were available ad libitum except during the exposure to the different behavioral paradigms. Mice were habituated to their new environment and handled for 1 week after arrival, and before starting the experimental procedure. The observer was blind to treatment in all the experiments. Animal procedures were conducted in accordance with the guidelines of the European Communities Directive 86/609/EEC regulating animal research and approved by the local ethical committee (CEEA-IMAS-UPF).

\section{Drugs}

(-)-Nicotine hydrogen tartrate salt [(-)-1-methyl-2(3-pyridyl)pyrrolidine] (Sigma) was dissolved in physiological saline $(0.9 \% \mathrm{NaCl})$ and administered by subcutaneous route in a volume of $10 \mathrm{ml} / \mathrm{kg}$ body weight. For the self-administration study, the $\mathrm{pH}$ of nicotine solution was adjusted to 7.4 and was contingently administered by intravenous route. All nicotine doses were calculated as nicotine hydrogen tartrate salt. SB334867 (Tocris Bioscience) was dissolved in $1 \%$ (2-hydroxypropyl)- $\beta$-cyclodextrin (Sigma) and 10\% DMSO in 90\% distilled water and administered by intraperitoneal route in a volume of $5 \mathrm{ml} / \mathrm{kg}$ body weight at the doses of 5 and $10 \mathrm{mg} / \mathrm{kg}$. The SB334867 doses were based on previous studies (Rodgers et al., 2001) and a pilot experiment testing the effects of this antagonist on the hyperactivity induced by Hcrt-1 in C57BL/6J mice (supplemental Fig. 1, available at www.jneurosci.org as supplemental material). Hcrt-1 and colchicine (Sigma) were dissolved in physiological saline and administered by intracerebroventricular route. Antalarmin was dissolved in cremophor/ethanol at 2:1 and was administered subcutaneously in a volume of $10 \mathrm{ml} / \mathrm{kg}$ body weight at the dose of $30 \mathrm{mg} / \mathrm{kg}$
(Pañeda et al., 2009). Ketamine hydrochloride (100 mg/kg) (Imalgène $1000)$ and xylazine hydrocloride $(20 \mathrm{mg} / \mathrm{kg}$ ) (Sigma) were mixed and dissolved in ethanol (5\%) and distilled water (95\%). This anesthetic mixture was administered intraperitoneally in a volume of $10 \mathrm{ml} / \mathrm{kg}$ body weight. Thiopental sodium ( $5 \mathrm{mg} / \mathrm{ml}$ ) (Braun Medical S.A.) was dissolved in distilled water and delivered through the intravenous catheter.

\section{Cannulation and intracerebroventricular infusions}

Colchicine and Hcrt-1 were infused intracerebroventricularly for CRF and arginine-vasopressin (AVP) immunodetection and the reinstatement study, respectively. Mice were anesthetized with a ketamine/xylazine mixture and mounted on a stereotaxic apparatus with a flat skull (Paxinos and Franklin, 1997). A small hole was drilled on the left or the right side of the skull randomly and the cannula (30 gauge, $10 \mathrm{~mm}$ long) was implanted vertically into the left/right lateral ventricle at the following coordinates relative to bregma according to the atlas of Paxinos and Franklin (1997): anteroposterior, $-0.22 \mathrm{~mm}$; mediolateral, $+1.00 /$ $-1.00 \mathrm{~mm}$; and dorsoventral, $-2.25 \mathrm{~mm}$. The cannula was fixed to the skull with dental cement. Mice were then housed individually and allowed 1 additional day of postoperative recovery before handling. Drugs were infused into the lateral ventricle of freely moving mice by connecting the cannula to polyethylene tubing (inner diameter, $0.28 \mathrm{~mm}$; outer diameter, $0.61 \mathrm{~mm}$ ) attached to a $10 \mu \mathrm{l}$ Hamilton micro syringe at a constant rate of $1 \mu \mathrm{l} / \mathrm{min}$ during $1 \mathrm{~min}$ using a multiple micro syringe driven pump (Harvard 22, Harvard Apparatus). Polyethylene tubing was removed from the cannula $1 \mathrm{~min}$ after infusions to prevent drug reflux. $0.05 \%$ methylene blue solution (Sigma) was perfused under the same experimental conditions to check the correct position of the cannula at the end of the experiment.

\section{Acute behavioral tests}

Pharmacological (SB334867 administration) and genetic (preprohypocretin $\mathrm{KO}$ mice) approaches were used in this set of experiments. For the pharmacological studies, mice received an injection of SB334867 (5 mg/ $\mathrm{kg}$, i.p.) or vehicle $30 \mathrm{~min}$ before the acute administration of nicotine or saline.

The changes in horizontal locomotor activity induced by acute administration of nicotine $(1,3$, and $6 \mathrm{mg} / \mathrm{kg}$, s.c.) or saline were measured by using individual locomotor activity boxes $(9 \times 20 \times 11 \mathrm{~cm}$, Imetronic $)$, as previously described (Berrendero et al., 2005). Mice were placed in the locomotor cages $5 \mathrm{~min}$ after drug injection, and activity was recorded for $10 \mathrm{~min}$ in a low luminosity environment (20-25 lux). The antinociceptive responses for each mouse were determined 15 and 16 min after nicotine $(1,3$, and $6 \mathrm{mg} / \mathrm{kg}$, s.c.) or saline administration using the tailimmersion and the hot-plate test respectively, as previously reported (Berrendero et al., 2005). In the tail-immersion test, the latency to a rapid flick of the tail was taken as the endpoint, and the maximum latency allowed was $5 \mathrm{~s}$. The threshold evaluated was the jumping response in the hot-plate test. In absence of jumps, a $240 \mathrm{~s}$ cutoff was used to prevent tissue damage. The data obtained were expressed as percentage of maximum possible effect (MPE) using the following equation: $\% \mathrm{MPE}=$ $[$ (test latency - control latency)/(cutoff time - control latency) $] \times 100$. The effects of nicotine $(0.05$ and $0.8 \mathrm{mg} / \mathrm{kg}$, s.c.) on anxiety-like responses were evaluated using the elevated plus-maze 5 min after nicotine or saline administration, as previously reported (Balerio et al., 2005). Each mouse was placed in the central neutral area facing one of the open arms and observed during $5 \mathrm{~min}$. Results are expressed as the percentage of time spent in the open arms.

\section{Immunofluorescence studies}

Tissue preparation. For CRF and AVP detection colchicine $(7 \mu \mathrm{g} / 1 \mu \mathrm{l}$, i.c.v.) was injected $24 \mathrm{~h}$ before acute drug treatment. Blockade of axonal transport is essential for localization of significant CRF immunoreactivity in neuronal cell bodies. A low dose was selected to avoid c-Fos induction by colchicine itself (Valentine et al., 1996). One hour after nicotine challenge, mice were transcardially perfused with $4 \%$ paraformaldehyde (PFA), postfixed in the same fixative for $4 \mathrm{~h}\left(4^{\circ} \mathrm{C}\right)$ and cryoprotected overnight in a solution of $30 \%$ sucrose at $4^{\circ} \mathrm{C}$. Coronal frozen sections were made at $30 \mu \mathrm{m}$ on a freezing microtome and stored in a $5 \%$ sucrose solution at $4^{\circ} \mathrm{C}$ until use. 
Immunofluorescence. A previously described protocol (Balerio et al., 2004) was adapted for immunofluorescence. Sections were incubated with the primary antibody in 3\% normal goat serum and $0.3 \%$ Triton $\mathrm{X}-100$ in $0.1 \mathrm{~m} \mathrm{~PB}$ (NGS-T-PB) overnight at $4^{\circ} \mathrm{C}$ (for the Hcrtr-1 detection the incubation was extended to $36 \mathrm{~h}$ ). Next day, sections were incubated with the secondary antibody at room temperature in NGS-T-PB for $2 \mathrm{~h}$. After incubation, sections were rinsed and mounted immediately after onto glass slides coated with gelatin in Mowiol mounting medium. For c-Fos and Hcrt-1 detection a rabbit polyclonal antiserum (1:1000) (Ab-5; Calbiochem) and a mouse monoclonal antibody (1:500) (R\&D Systems) were used respectively. Guinea-pig polyclonal antibodies (1: 1000) (Peninsula Laboratories) were used for CRF and AVP detection. For the Hcrtr-1 detection rabbit polyclonal antibody (1:50) (Alpha Diagnostic) was used. As secondary antibodies, Cy3-conjugated goat antirabbit and Cy2-conjugated goat anti-mouse and anti-guinea pig IgG (Jackson ImmunoResearch) were used (1:500).

c-Fos quantification. The stained sections of the brain were analyzed at $10 \times$ objective using a Leica DMR microscope equipped with a digital camera Leica DFC 300FX. ImageJ software was used for the quantification of c-Fos-positive nuclei. Two samples of 3-5 mice per each group were quantified. Circular particles were analyzed in transformed binary images using a constant region of interest (ROI). The threshold was adjusted to distinguish the particles from the background.

Colocalization analysis. For the colocalization analysis of c-Fos or Hcrtr-1 with CRF/AVP and c-Fos with Hcrt-1, the stained sections were analyzed at $40 \times$ objective with oil-immersion using a Leica SP2 confocal microscope adapted to an inverted Leica DM IRBE microscope. The quantification of CRF/AVP or Hcrt-1-positive cells for c-Fos was done manually in 3-4 different samples of 3 mice.

\section{Reinstatement of nicotine-seeking behavior}

Apparatus. The experiments were conducted in mouse operant chambers (model ENV-307A-CT; Med Associates Inc.) equipped with two holes, one randomly selected as the active hole and the other as the inactive hole. Pump noise and stimuli lights (cues), one located inside the active hole and the other above it were paired with the delivery of the reinforcer. Nicotine $(85.5 \mu \mathrm{g} / \mathrm{kg}$ per infusion) or saline was delivered in a volume of $23.5 \mu$ lover $2 \mathrm{~s}$ via a syringe that was mounted on a microinfusion pump and connected via Tygon tubing to a single channel liquid swivel and to the mouse intravenous catheter.

Jugular vein catheterization. Mice were anesthetized with a ketamine/ xylazine mixture and then implanted with indwelling intravenous SILASTIC catheters on their right jugular vein as previously described (Soria et al., 2005). Briefly, a $6 \mathrm{~cm}$ length of SILASTIC tubing $(0.3 \mathrm{~mm}$ inner diameter, $0.6 \mathrm{~mm}$ outer diameter) (SILASTIC, Dow Corning) was fitted to a 22-gauge steel cannula (Semat) that was bent at a right angle and then embedded in a cement disk (Dentalon Plus, Heraeus) with an underlying nylon mesh. The catheter tubing was inserted 1.3 $\mathrm{cm}$ into the right jugular vein and anchored with suture. The remaining tubing ran subcutaneously to the cannula, which exited at the midscapular region. All incisions were sutured and coated with antibiotic ointment (Bactroban; GlaxoSmithKline). After surgery, animals were allowed to recover for $5 \mathrm{~d}$ before initiation of self-administration sessions.

Self-administration training. Slight modifications were done to the operant model recently described (Martín-García et al., 2009). One h daily self-administration sessions were conducted consecutively for $10 \mathrm{~d}$. Mice were trained under a fixed ratio 1 (FR1) schedule of reinforcement with a $10 \mathrm{~s}$ time-out. Each daily session started with a priming injection of the drug. The stimuli light together with the pump noise (environmental cues) signaled delivery of nicotine infusion. During the $10 \mathrm{~s}$ time-out period, the cue light was off and no reward was provided after nosepoking on the active hole. Responses on the inactive hole and all the responses elicited during the $10 \mathrm{~s}$ time-out period were also recorded. The session was terminated after 50 reinforcers were delivered or after $1 \mathrm{~h}$, whichever occurred first. The criteria for the acquisition of selfadministration behavior were achieved when in three consecutive sessions: (1) mice maintained a stable responding with $<20 \%$ deviation from the mean of the total number of reinforcers earned ( $80 \%$ stability);
(2) at least 75\% responding on the active hole, and (3) a minimum of 6 reinforcers per session. The patency of intravenous catheters was evaluated at the end of nicotine self-administration training by an infusion of $0.05-0.10 \mathrm{ml}$ of thiopental sodium through the catheter. If prominent signs of anesthesia were not apparent within $3 \mathrm{~s}$ of the infusion the mouse was removed from the experiment. Only animals with patent catheter that met all the acquisition criteria were moved to the extinction phase. Mice were divided in 2 groups depending on the reinstatement procedure. Animals selected for the footshock stress-induced reinstatement were allowed to rest for $1 \mathrm{~d}$ after the end of the self-administration training before the beginning of the extinction sessions. Animals selected to receive Hcrt- 1 in the lateral ventricle were cannulated $1 \mathrm{~d}$ after the end of the self-administration training and allowed to rest for one additional day before the beginning of the extinction sessions. Intracerebroventricular injections were performed after mice achieved the extinction criteria (average of $25 \pm 2$ daily sessions), when mice were completely recovered from the effects of surgery.

Extinction. During the extinction period, nicotine and cues were not available after nose-poking in the active hole. Mice were given $1 \mathrm{~h}$ daily sessions $7 \mathrm{~d}$ per week until reaching the extinction criterion during a maximum of $50 \mathrm{~d}$. The criterion was achieved when responses on the active hole were $<30 \%$ of the mean responses obtained during the $3 \mathrm{~d}$ achieving the acquisition criteria across 3 consecutive extinction sessions. Only animals that reached the extinction criterion were evaluated for nicotine reinstatement induced by Hcrt-1 or footshock. Tests for reinstatement were conducted under the same conditions used in the extinction phase.

Hcrt-1-induced reinstatement. The first day after achieving the extinction criterion, mice received an intracerebroventricular vehicle infusion preceded by vehicle, SB334867 (5 mg/kg, i.p.) or antalarmin $(30 \mathrm{mg} / \mathrm{kg}$, s.c.). SB334867 and antalarmin were administered $30 \mathrm{~min}$ and $1 \mathrm{~h}$ before the intracerebroventricular infusions respectively, as previously reported (Boutrel et al., 2005; Pañeda et al., 2009). The next day, mice received an intracerebroventricular Hcrt-1 $(0.75 \mathrm{nmol} / 1 \mu \mathrm{l})$ infusion preceded by the same vehicle, SB334867 or antalarmin. Subsequently, mice were given extinction sessions until reaching the extinction criterion and were infused with an intracerebroventricular vehicle infusion to rule out any order effect on Hcrt-1-induced reinstatement. Tests for reinstatement were conducted $10 \mathrm{~min}$ after the intracerebroventricular vehicle or Hcrt-1 infusion. The dose selected for Hcrt-1 infusion was based on previous studies (Boutrel et al., 2005; Nair et al., 2008).

Footshock stress-induced reinstatement. The group of mice exposed to footshock stress received intermittent footshock stimuli (5 footshocks separated by a 1 min period without shock) with an intensity of $0.22 \mathrm{~mA}$ during 5 min immediately before the reinstatement session, as previously reported (Martín-García et al., 2009). Mice were pretreated with SB334867 (5 and $10 \mathrm{mg} / \mathrm{kg}$, i.p.), antalarmin (30 mg/kg, s.c.) or vehicle before applying the footshock. SB334867 and antalarmin were administered $30 \mathrm{~min}$ and $1 \mathrm{~h}$ before the footshock, respectively.

\section{Operant conditioning maintained by water}

To discard any possible learning or memory impairment produced by the administration of the Hcrtr-1 antagonist SB334867 (5 mg/kg, i.p.) on operant conditioning, a different group of $\mathrm{C} 57 \mathrm{BL} / 6 \mathrm{~J}$ mice were trained to acquire nose-poking operant behavior maintained by water. Slight modifications were done to the protocol previously described (Soria et al., 2005). Mice were first deprived of water during $2 \mathrm{~d}$ (20 min of free water was provided daily) and this same water deprivation regime was maintained during the whole evaluation of water-maintained operant behavior. Food was available ad libitum during this experimental phase. Two days after starting water deprivation, mice were trained to nose-poke for water in the operant chambers. SB334867 or vehicle was administered 30 min before starting each session. One hour daily operant sessions were conducted $7 \mathrm{~d}$ per week during $10 \mathrm{~d}$. The house light was on at the beginning of the session for $3 \mathrm{~s}$ and off during the remaining duration of the session. Operant responding maintained by water was conducted in the same operant chambers described above for nicotine self-administration experiments except that a liquid dipper was used instead of an infusion pump and operant nose-poking responses were maintained by 
delivery of $10 \mu \mathrm{l}$ of water over $10 \mathrm{~s}$. Mice were trained under a fixed ratio 1 (FR1) schedule of reinforcement. A $20 \mathrm{~s}$ time-out period was established after each reinforcement. During this $20 \mathrm{~s}$ period, the cue light was off and no reward was provided on the active hole. Responses on the inactive hole and all the responses during the $20 \mathrm{~s}$ time-out period were also recorded. The session was terminated after 100 reinforcers were delivered or after $1 \mathrm{~h}$, whichever occurred first. The criteria for the acquisition were achieved when in three consecutive sessions: (1) mice maintained a stable responding with $<20 \%$ deviation from the mean of the total number of reinforcers earned ( $80 \%$ stability); (2) at least $75 \%$ responding on the active hole, and (3) a minimum of 10 reinforcers per session. Mice reaching these criteria were changed to a progressive ratio (PR) schedule of reinforcement on day 11 , in which the response requirement to earn a reinforcer escalated according to the following series: 1-2-3-5-12-18-27-40-60-90-135-200-300-450-675-1000. The PR session lasted $4 \mathrm{~h}$ or until mice did not complete the ratio for delivery of one reinforcer within $1 \mathrm{~h}$, and was performed only once.

\section{Statistical analysis}

Two-way ANOVA was used to analyze the acute effects of nicotine on locomotor activity, antinociception and anxiety-like effects with SB334867 pretreatment/genotype and nicotine treatment as between-subject factors of variation. Subsequent one-way ANOVA and post hoc comparisons (Newman-Keuls) were used when required. The percentage of hypocretin cells expressing c-Fos in the perifornical and dorsomedial hypothalamic areas (PFA/DMH) as well as in the lateral hypothalamus (LH) after nicotine injection was analyzed by Student's $t$ test. To analyze the acquisition of nicotine self-administration, two-way ANOVA with repeated measures with the factors hole and day was used. The analysis was followed by one-way ANOVA for each day of training. Pearson's $\chi^{2}$ test was used to compare the percentage of acquisition between animals trained to self-administer nicotine and saline. To evaluate the reinstatement of nicotine-seeking behavior, animals were divided in different groups corresponding to each experimental condition used to induce reinstatement (Hcrt-1 administration or electric footshock in animals pretreated with vehicle, SB334867 or antalarmin). Two-way ANOVA with repeated measures with the factors hole and experimental phase followed by corresponding one-way ANOVA and post hoc analyses (Newman-Keuls) were performed when required. All the animals reaching the reinstatement phase were included in this analysis. The level of significance was $p<0.05$ in all experiments.

\section{Results}

\section{Hcrts regulate the anxiogenic-like effects of nicotine}

Acute nicotine administration $(0.8 \mathrm{mg} / \mathrm{kg}$, s.c.) induces anxiogenic-like effects in the mouse elevated plus-maze (Balerio et al., 2005). We found that pretreatment with the Hcrtr-1 antagonist SB334867 and preprohypocretin gene deletion blocked the anxiogenic-like effects of nicotine (Fig. $1 A, B$ ). Two-way ANOVA for the percentage of time spent in the open arms showed a significant interaction between SB334867 pretreatment and nicotine treatment $\left(F_{(1,63)}=6.50, p<0.05\right)$. Subsequent one-way ANOVA showed a blockade of the anxiogenic-like effects of nicotine in SB334867-pretreated mice $(p<0.05)$ (Fig. $1 A)$. According to the pharmacological experiment, a significant interaction between nicotine treatment and genotype $\left(F_{(1,31)}=9.12, p<\right.$ 0.05 ) was revealed for the same parameter by two-way ANOVA. One-way ANOVA indicated the suppression of the anxiogeniclike effects of nicotine in preprohypocretin $\mathrm{KO}$ mice $(p<0.05)$ (Fig. $1 B$ ). In contrast, SB334867 administration did not modify the anxiolytic-like effects of nicotine $(0.05 \mathrm{mg} / \mathrm{kg}$, s.c. $)$ in the elevated plus-maze (supplemental Fig. $2 \mathrm{~A}$, available at www. jneurosci.org as supplemental material). Other acute effects of nicotine such as hypolocomotion and antinociception were not either influenced by preadministration of SB334867 or preprohypocretin gene deletion (supplemental Fig. 3, available at www. jneurosci.org as supplemental material). Together, these data
A

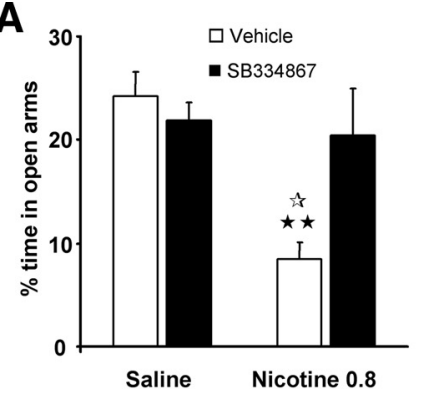

B
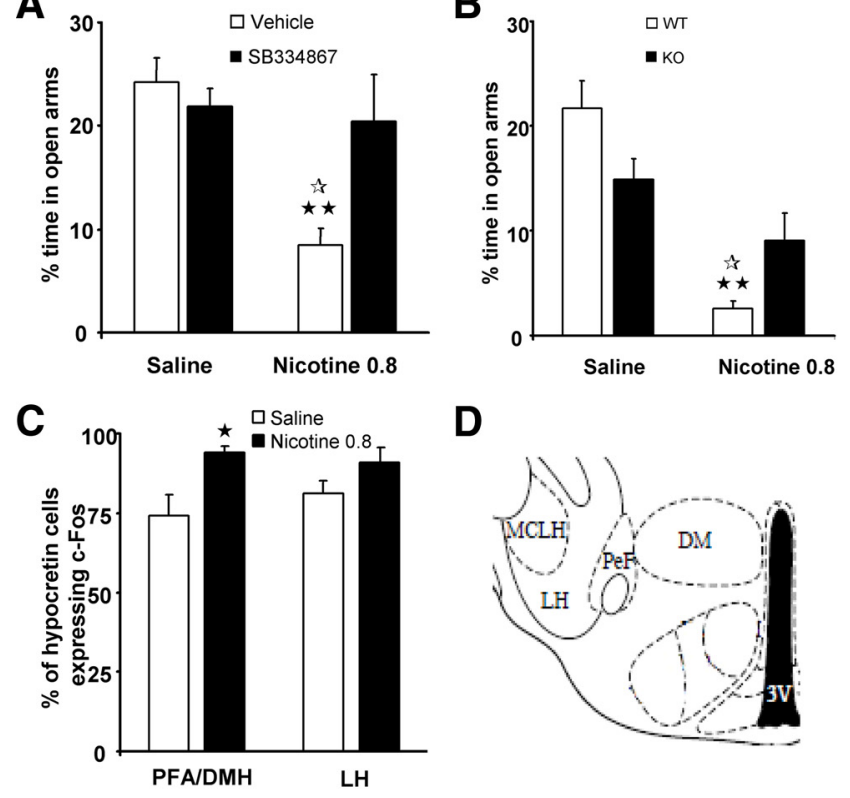

D

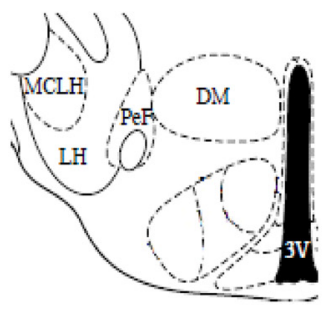

E
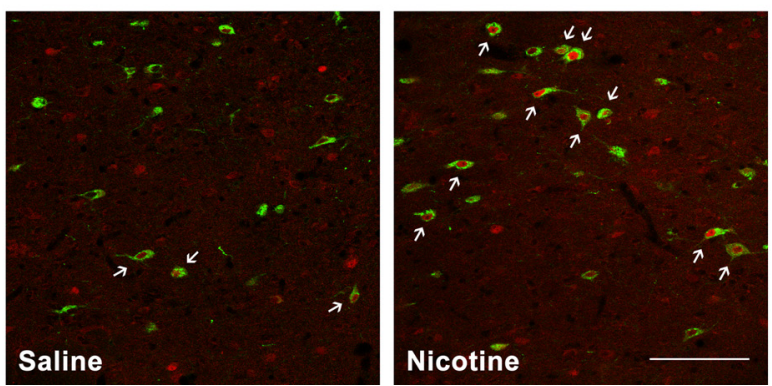

Figure 1. Modulation of the anxiogenic-like effects of nicotine by Hcrts. $A, B$, Percentage of time spent in the open arms of the elevated plus-maze in response to acute nicotine $(0.8 \mathrm{mg} / \mathrm{kg}$, s.c.) in vehicle ( $\square$ )- or SB334867 (5 mg/kg, i.p.) ( $\square$ )-pretreated C57BL/6J mice $(n=16-18$ mice per group) (A) and in wild-type $(\square)$ or preprohypocretin knock-out $(\square)$ mice ( $n=8-9$ mice per group) (B). SB334867 was administered $30 \mathrm{~min}$ before nicotine. C, Percentage of c-Fos-positive Hcrt-1-expressing neurons after saline or nicotine $(0.8 \mathrm{mg} / \mathrm{kg}$, s.c.) administration in the PFA/DMH ( $n=3$ mice per group) and the LH ( $n=3$ mice per group). Data are expressed as mean \pm SEM, ${ }^{\star} p<0.05,{ }^{\star \star} p<0.01$ compared with the control group; $p<$ 0.05 compared with K0 or SB334867-pretreated nicotine-treated mice (one-way ANOVA). $D$, Schematic anatomic representation of $\mathrm{LH}$ subdivisions adapted from Paxinos and Franklin's stereotaxic atlas (Paxinos and Franklin, 1997). Labeled areas delineate regions where c-Fos expression was examined. $\boldsymbol{E}$, Representative images of sections of the PFA/DMH obtained via confocal microscopy after direct double labeling combining rabbit polyclonal antiserum to c-Fos with mouse monoclonal antibody to Hcrt-1. Arrowheads indicate c-Fos-positive Hcrt-1expressing neurons. Scale bar, $100 \mu \mathrm{m}$.

indicate that hypocretins selectively modulate the acute anxiogenic-like effects of nicotine.

To further evaluate the role of Hcrt neurons in the anxiogeniclike effects of nicotine, we studied the possible activation of these cells by using double label immunofluorescence of c-Fos with Hcrt-1 in the perifornical and dorsomedial hypothalamic areas (PFA/DMH) as well as in the lateral hypothalamus (LH). Nicotine $(0.8 \mathrm{mg} / \mathrm{kg}$, s.c. $)$ induced a significant increase in the percentage of Hcrt-1 cells expressing c-Fos (Fig. 1C,E) in the PFA/DMH $(p<0.05)$, but no change was found in the LH (Fig. 1C). These data are in agreement with previous studies which suggest that Hcrt neurons located in the PFA/DMH respond to stressful events (Harris et al., 2005, 2007).

On the other hand, neurons expressing Hcrt-1 were not activated following the injection of a low dose of nicotine $(0.05 \mathrm{mg} /$ 
$\mathrm{kg}$, s.c.) which induces anxiolytic-like effects (supplemental Fig. $2 B$, available at www.jneurosci.org as supplemental material). This result is consistent with the behavioral study (supplemental Fig. 2A, available at www.jneurosci.org as supplemental material), and corroborates the lack of interaction between the Hcrt system and the anxiolytic-like effects of nicotine.

\section{Hcrts modulate the activation of the paraventricular nucleus of the hypothalamus induced by the anxiogenic dose of nicotine} We next determined the brain areas involved in the anxiogenic-like effects of nicotine (Singewald et al., 2003; Hsu et al., 2007) and the possible role of Hcrt transmission in this effect by using immunofluorescence of c-Fos, an immediate-early gene used as a functional anatomical marker of cellular activation (Kovács, 2008). Acute nicotine injection $(0.8 \mathrm{mg} /$ $\mathrm{kg}$, s.c.) induced an increase of c-Fos expression in the paraventricular nucleus of the hypothalamus (PVN) (Fig. 2A,B), and in the paraventricular nucleus of the thalamus (PVT) (supplemental Fig. 4, available at www.jneurosci.org as supplemental material). No increase in c-Fos expression was observed in other brain areas analyzed such as the central nucleus of the amygdala, cingulate cortex, medial and lateral septum, striatum, the bed nucleus of the stria terminalis and nucleus accumbens (supplemental Fig. 4, available at www.jneurosci.org as supplemental material). The previous administration of SB334867 or preprohypocretin gene deletion prevented the activation of the PVN induced by nicotine (Fig. $2 A-D$ ). In the pharmacological approach, two-way ANOVA showed a significant interaction between SB334867 pretreatment and nicotine treatment $\left(F_{(1,16)}=16.95, p<0.01\right)$. One-way ANOVA revealed a blockade of nicotine activation of the PVN due to SB334867 pretreatment $(p<0.01)$ (Fig. $2 A, C)$. In the genetic approach, two-way ANOVA also showed a significant interaction between genotype and nicotine treatment $\left(F_{(1,8)}=27.23, p<0.01\right)$. An abolishment of c-Fos expression induced by nicotine in the PVN of preprohypocretin deficient mice was revealed by one-way ANOVA $(p<0.01)$ (Fig. $2 B, D)$.

Again, the administration of the low dose of nicotine $(0.05$ $\mathrm{mg} / \mathrm{kg}$, s.c.) that produces anxiolytic-like effects did not increase the expression of c-Fos in the PVN (supplemental Fig. 2C, available at www.jneurosci.org as supplemental material), suggesting that this brain area is not involved in nicotine anxiolytic-like effects.

\section{Nicotine-induced activation of CRF and AVP-expressing} neurons located in the PVN is dependent on Hcrtr-1

CRF- and AVP-expressing neurons are the most important cell types involved in the regulation of anxiety and stress responses within the PVN (Lightman, 2008; Landgraf, 2005). Therefore, we asked whether these neurons located in the PVN were activated

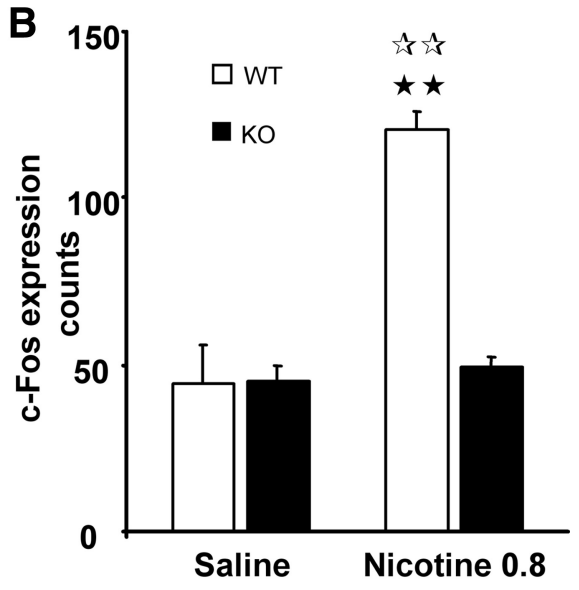

D WT-SAL
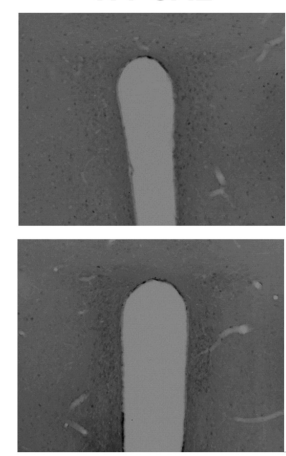

KO-SAL
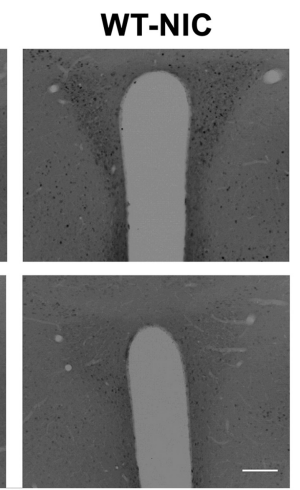

KO-NIC
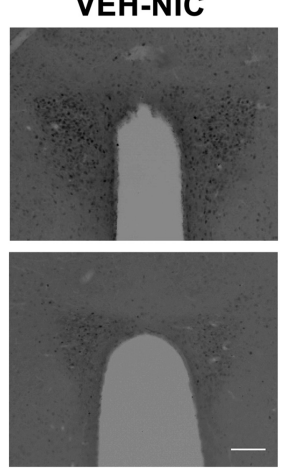

SB-NIC

icotine $(0.8$ $\mathrm{mg} / \mathrm{kg}$, s.c.) administration in vehicle ( $\square$ )- or SB334867 (5 mg/kg, i.p.) ( $\square$ )-pretreated C57BL/6J mice ( $n=5$ mice per group) (A) and in wild-type $(\square)$ or preprohypocretin knock-out $(\square)$ mice ( $n=3$ mice per group) (B). SB334867 was administered 30 min before nicotine. Quantification of c-Fos-positive nuclei in the PVN was performed by ImageJ software. Data are expressed as treated mice (one-way ANOVA). C, D, Representative images of the PVN obtained by microscopy after direct-labeling with rabbit polyclonal antiserum to c-Fos. Scale bar, $100 \mu \mathrm{m}$.

following the injection of nicotine $(0.8 \mathrm{mg} / \mathrm{kg}$, s.c. $)$ and the possible modulation of this effect by the Hcrtr-1. Acute nicotine treatment induced an increase of c-Fos expression in both CRFand AVP-expressing neurons (Fig. $3 A, B$ ) (supplemental Fig. 5, available at www.jneurosci.org as supplemental material for representative images), and SB334867 pretreatment prevented this activation. Thus, two-way ANOVA showed a significant interaction between SB334867 pretreatment and nicotine treatment $\left(F_{(1,8)}=\right.$ 37.00, $p<0.01$ and $F_{(1,8)}=14.07, p<0.01$ ), for CRF and AVP experiments respectively. One-way ANOVA revealed a blockade of the activation of CRF $(p<0.01)$ and $\operatorname{AVP}(p<0.05)$ neurons due to SB334867 pretreatment (Fig. $3 A, B$ ). On the contrary, the administration of a low dose of nicotine $(0.05 \mathrm{mg} / \mathrm{kg})$ was not effective to enhance the percentage of c-Fos-positive CRF (saline: $26.23 \pm 6.14 \%$; nicotine: $22.17 \pm 6.64 \%$ ) and AVP (saline: $21.26 \pm 1.07 \%$; nicotine: $18.68 \pm 2.01 \%$ ) neurons of the PVN. These data indicate that Hcrtr-1 is necessary for CRF- and AVPexpressing cell activation in the PVN after nicotine $(0.8 \mathrm{mg} / \mathrm{kg}$, s.c.) treatment. We next investigated whether these neurons expressed Hcrtr-1 by using double label immunofluorescence. As shown in Figure 3, $C$ and D, Hcrtr-1 is expressed by both neuronal types within the PVN.

Together, our results suggest that Hcrts participate in the acute anxiogenic-like effects of nicotine. This behavioral re- 

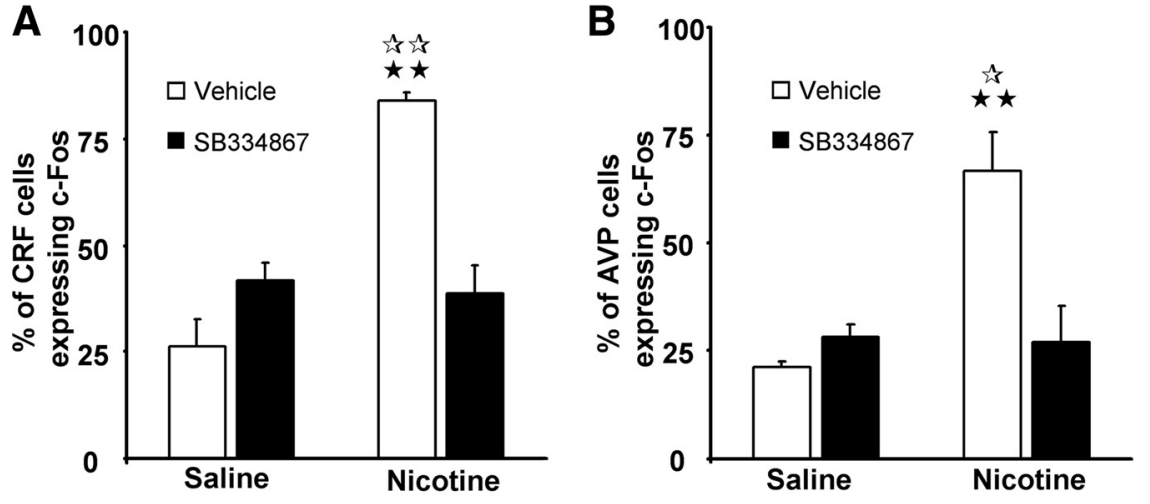

C
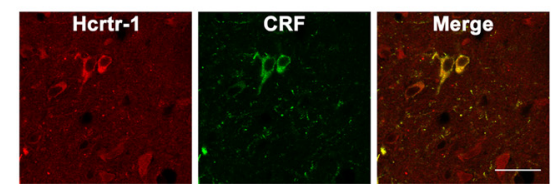

D
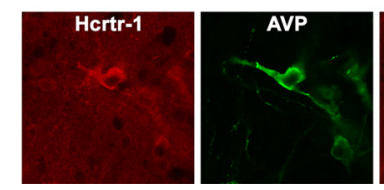

Figure 3. Nicotine-induced activation of CRF and AVP neurons of the PVN is dependent on Hcrtr-1. A, B, Percentage of C-Fospositive CRF $(\boldsymbol{A})$ - and AVP $(\boldsymbol{B})$-expressing neurons after nicotine $(0.8 \mathrm{mg} / \mathrm{kg}$, s.c.) administration in vehicle ( $\square$ )- or SB334867 (5 $\mathrm{mg} / \mathrm{kg}$, i.p.) ( $\square$ )-pretreated (57BL/6J mice ( $n=3$ mice per group). SB334867 was administered $30 \mathrm{~min}$ before nicotine. Data are expressed as mean \pm SEM, ${ }^{\star \star} p<0.01$ compared with the control group; $p<0.05$, ${ }^{\circ \star 2} p<0.01$ compared with SB334867pretreated nicotine-treated mice (one-way ANOVA). Representative images of sections of the PVN are shown in supplemental Figure 5 (available at www.jneurosci.org as supplemental material). C, D, CRF- and AVP-expressing neurons of the PVN contain Hcrtr-1. Rabbit polyclonal antibodies to Hcrtr-1 were combined with guinea-pig polyclonal antibodies to CRF (C) and AVP (D). Scale bar for colocalization images, $25 \mu \mathrm{m}$.

sponse is associated to a stimulation of CRF and AVP neurons in the PVN that is dependent on Hcrt transmission. However, the possible involvement of other cellular types of the PVN in the modulation that Hcrts exert on this nicotine behavioral response cannot be excluded. Thus, the anxiogenic-like effects of nicotine were not blocked by the pretreatment with the CRF1 receptor antagonist antalarmin (supplemental Fig. 6, available at www.jneurosci.org as supplemental material).

\section{Acquisition, maintenance and extinction of nicotine self-administration}

Mice were trained to self-administer nicotine $(85.5 \mu \mathrm{g} / \mathrm{kg}$ per infusion) during $10 \mathrm{~d}$. Two-way ANOVA with repeated measures revealed a significant interaction between the day of training and the hole $\left(F_{(9,441)}=9.27, p<0.01\right)$, indicating a progress in operant responding for nicotine across days (Fig. $4 A$ ). The acquisition criteria (stability of $80 \%$ in active responses, $75 \%$ of responses on the active hole and 6 daily infusions minimum, all these criteria during 3 consecutive days) were achieved in $8 \pm 0.2 \mathrm{~d}$ by $71 \%$ of the mice that were trained to selfadminister nicotine whereas only $27 \%$ of the mice trained to self-administer saline achieved these criteria (data not shown) $\left(\chi^{2}=126.32, p<0.01\right)$. Mice that reached the acquisition criteria for nicotine self-administration underwent an extinction schedule (Fig. 4 B). The extinction criterion $(<30 \%$ of the mean responses obtained during the $3 \mathrm{~d}$ achieving the acquisition criteria across 3 consecutive days of extinction) was achieved by $63 \%$ of mice. This criterion was reached after an average of $25 \pm$ 2 daily sessions of extinction. During the first session of extinction mice showed an increase in the number of responses in the active hole $(27 \pm 2)$ compared with the responses of the last day of nicotine self-administration training $(13 \pm 1)$. This 'extinction burst' behavior confirms that mice developed a reliable operant nicotine self-administration behavior (Cooper et al., 1987). Animals

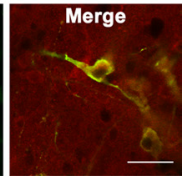

that met the criterion for extinction were tested for reinstatement of nicotineseeking behavior. Reinstatement studies were performed using a between-subjects design. For this purpose, animals were divided in 7 different groups depending on the experimental conditions for reinstatement. Four groups of mice were used for stress-induced reinstatement experiments (treated with vehicle, SB334867 5 $\mathrm{mg} / \mathrm{kg}$, SB334867 $10 \mathrm{mg} / \mathrm{kg}$ or antalarmin $30 \mathrm{mg} / \mathrm{kg}$ ) and 3 groups were used for Hcrt-1-induced reinstatement (treated with vehicle, SB334867 $5 \mathrm{mg} / \mathrm{kg}$ or antalarmin $30 \mathrm{mg} / \mathrm{kg}$ ). Two-way ANOVA with repeated measures was performed to exclude any bias on the acquisition levels of nicotine selfadministration among the groups of mice tested in the different experimental conditions of reinstatement. As expected, two-way ANOVA revealed a significant effect of the day of training $\left(F_{(9,387)}=3.97, p<0.001\right)$, but not significant effects of the different experimental groups selected for the reinstatement experiments $\left(F_{(6,43)}=0.976, \mathrm{NS}\right)$ nor interaction between both factors $\left(F_{(54,387)}=1.15, \mathrm{NS}\right)$, indicating that there were no differences in nose-poking during the $10 \mathrm{~d}$ of self-administration training between the different groups of mice used in the reinstatement studies.

\section{SB334867 does not affect operant conditioning maintained \\ by water}

To exclude any nonspecific effect on learning or memory due to the treatment with SB334867 (5 mg/kg, i.p.), we studied the effects of this antagonist in operant conditioning maintained by water in water-deprived mice. The treatment with SB334867 did not produce any effect on this operant performance as indicated by the lack of differences between groups pretreated with vehicle and SB334867 on nose-poke behavior maintained by water (supplemental Fig. 7, available at www.jneurosci.org as supplemental material). Thus, the total number of animals pretreated with vehicle or SB334867 (5 mg/kg, i.p.) acquired the operant behavior. The mean number of days needed to achieve the acquisition criteria was $5.70 \pm 0.42$ for vehicle-pretreated mice and $5.67 \pm 0.69$ for SB334867-pretreated animals. In addition, the breaking point in the progressive ratio schedule of reinforcement was similar in both groups of animals (vehicle-pretreated mice: $69 \pm 7.37$; SB334867-pretreated mice: $83.2 \pm 18.09$ ).

\section{The Hcrtr-1 antagonist SB334867, but not the CRF1 receptor} antagonist antalarmin, blocks the reinstatement of nicotine-seeking induced by Hcrt-1

We assessed the ability of Hcrt-1 $(0.75 \mathrm{nmol} / 1 \mu$ l, i.c.v. $)$ to reinstate nicotine-seeking behavior and the possible role of Hcrtr-1 and CRF1 receptor in this effect. For the statistical analysis, mice were divided in 3 different groups depending on the treatment preceding the Hcrt-1 infusion: vehicle, SB334867 $5 \mathrm{mg} / \mathrm{kg}$ or antalarmin $30 \mathrm{mg} / \mathrm{kg}$. Statistical analysis is summarized in Tables 1 and 2. Tests for reinstatement were conducted under the same conditions used in the extinction phase. The first day after reaching the extinction criterion, mice were infused with an intracere- 

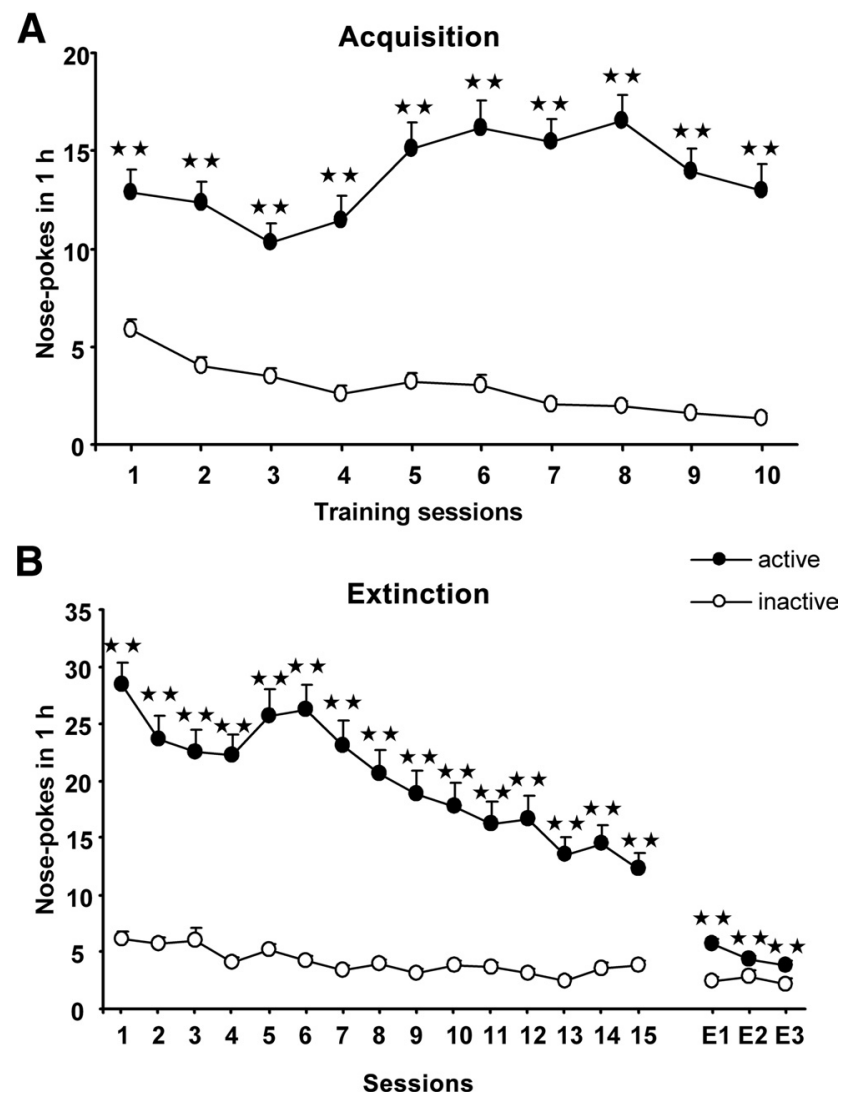

Figure 4. Acquisition and extinction of nicotine self-administration behavior. $\boldsymbol{A}, \boldsymbol{B}$, Mean number of nose-poking responses in the active $(O)$ and inactive $(\bigcirc)$ holes during nicotine self-administration training and extinction. The complete group of animals used in the different experiments of reinstatement is shown $(n=50)$. $A$, Mice were trained daily in $1 \mathrm{~h}$ sessions to obtain nicotine $(85.5 \mu \mathrm{g} / \mathrm{kg}$ per infusion) during $10 \mathrm{~d}$ under a fixed ratio 1 schedule of reinforcement. $\boldsymbol{B}$, The first $15 \mathrm{~d}$ of the extinction phase and the last $3 \mathrm{~d}$ achieving the extinction criterion (E1, E2, E3) are shown. Sessions were conducted daily and lasted for $1 \mathrm{~h}$. Animals were no longer reinforced after an active nose-poke. Data are expressed as mean $\pm \mathrm{SEM},{ }^{\star \star} p<0.01$ comparison between holes (one-way ANOVA).

broventricular vehicle infusion preceded by vehicle, SB334867 5 $\mathrm{mg} / \mathrm{kg}$ or antalarmin $30 \mathrm{mg} / \mathrm{kg}$. The 3 groups of mice maintained the same nose-poking levels when compared with the performance during the extinction sessions (Fig. 5), ruling out any intrinsic effects of the intracerebroventricular vehicle injection and indicating that SB334867 and antalarmin do not affect operant responding. The next day, mice received an intracerebroventricular Hcrt-1 infusion preceded by vehicle, SB334867 $5 \mathrm{mg} / \mathrm{kg}$ or antalarmin $30 \mathrm{mg} / \mathrm{kg}$. The animals that received the combination of vehicle + Hcrt-1 clearly reinstated the previously extinguished nicotine-seeking behavior, but pretreatment with SB334867 completely blocked this effect (Fig. 5). This blockade indicates a role for Hcrtr-1 in the reinstatement of nicotineseeking behavior induced by Hcrt-1. In contrast to the blockade induced by the Hcrtr-1 antagonist, antalarmin did not modify Hcrt-1-induced reinstatement (Fig. 5), which excludes the participation of CRF1 receptor in this Hcrt-1 behavioral response. Subsequently, mice were given extinction sessions until they reached the extinction criterion and were tested again for reinstatement by vehicle intracerebroventricular injection. No increase in nose-poking responding was observed after this second vehicle injection excluding any order effect in the reinstatement of nicotine-seeking induced by Hcrt-1 (data not shown).
The CRF1 receptor antagonist antalarmin, but not the Hcrtr-1 antagonist SB334867, blocks footshock-induced reinstatement of nicotine-seeking behavior

We next examined the role of Hcrtr-1 and CRF1 receptor in the regulation of the reinstatement of nicotine-seeking induced by footshock stress. For the statistical analysis, mice were divided in 4 different groups depending on the treatment preceding the electric footshock: vehicle, SB334867 $5 \mathrm{mg} / \mathrm{kg}$, SB334867 10 $\mathrm{mg} / \mathrm{kg}$ or antalarmin $30 \mathrm{mg} / \mathrm{kg}$. Statistical analysis is summarized in Tables 1 and 2. Mice pretreated with SB334867 (5 and 10 $\mathrm{mg} / \mathrm{kg}$, i.p.) reinstated the behavior after footshock exposure similarly to those pretreated with vehicle (Fig. 6), suggesting that Hcrtr-1 does not participate in footshock stress-induced reinstatement of nicotine-seeking behavior. A higher dose of this antagonist was not used due to the decrease of locomotor activity observed at the dose of $15 \mathrm{mg} / \mathrm{kg}$ in C57BL/6J mice, which could difficult the interpretation of the data (supplemental Fig. 8, available at www.jneurosci.org as supplemental material). On the contrary to SB334867, antalarmin blocked footshock stress-induced reinstatement of nicotine-seeking (Fig. 6), suggesting an involvement of CRF1 receptor in this nicotine behavioral response.

\section{Discussion}

Our study demonstrates that Hcrts participate in the acute anxiogenic-like effects of nicotine. This behavioral response was associated to a stimulation of CRF and AVP neurons in the PVN that was dependent on Hcrt transmission. The possible involvement of other cellular types of the PVN in the modulation that Hcrts exert on the anxiogenic-like effects of nicotine cannot be ruled out since the single blockade of the CRF1 receptor is not sufficient to abolish this nicotine behavioral response. Moreover, we also show for the first time that Hcrt-1, likely via Hcrtr-1 activation, induces reinstatement of nicotine-seeking behavior. The mechanism by which Hcrt-1 induces reinstatement seems to be independent of the CRF system. Thus, the CRF1 receptor antagonist antalarmin did not block the effects of Hcrt-1 on reinstatement whereas the Hcrtr-1 antagonist SB334867 did not modify the CRF-dependent footshock-induced reinstatement of nicotine-seeking.

Nicotine has been shown to produce anxiolytic- and anxiogenic-like responses depending on the dose used, and to activate the PVN and the HPA axis in rodents (Valentine et al., 1996; Loughlin et al., 2006; Lutfy et al., 2006; Shram et al., 2007). Low doses of nicotine usually induce anxiolytic-like effects whereas higher doses cause the opposite response in mice (Balerio et al., 2005). Our results demonstrate a correlation between the anxiogenic-like effects of nicotine and the consequent activation of CRF and AVP neurons in the PVN. Previous administration of the selective Hcrtr-1 antagonist SB334867 or the deletion of preprohypocretin gene blocked the anxiogenic-like response of nicotine in the elevated plus-maze. This effect was less robust in the case of the mutant animals probably due to the mild hypolocomotion (supplemental Fig. $3 B$, available at www.jneurosci.org as supplemental material) shown by these mice. Furthermore, nicotine-induced c-Fos expression in the PVN was also completely reversed by SB334867 and in mice lacking the preprohypocretin gene. In agreement, the activation of CRF and AVP cells was also reduced by pretreatment with the Hcrtr-1 antagonist. However, the anxiolytic-like effects of nicotine were not related to the activation of CRF and AVP neurons in the PVN. Hcrt containing-neurons are restricted to the lateral hypothalamus and their projections are widely distributed in the CNS 
Table 1. Statistical values obtained by two-way ANOVA with repeated measures in the factors hole (active vs inactive) and experimental phase (acquisition, extinction, reinstatement) for each reinstatement condition

\begin{tabular}{|c|c|c|c|c|c|c|}
\hline & \multicolumn{2}{|l|}{ Hole } & \multicolumn{2}{|l|}{ Experimental phase } & \multicolumn{2}{|l|}{ Interaction } \\
\hline & Fvalue & $p$ value & Fvalue & $p$ value & Fvalue & $p$ value \\
\hline Vehicle + hypocretin-1 & $F_{(1,8)}=101.802$ & $<0.001$ & $F_{(3,24)}=18.928$ & $<0.001$ & $F_{(3,24)}=22.109$ & $<0.001$ \\
\hline SB334867 5 mg/kg + hypocretin-1 & $F_{(1,3)}=4.628$ & NS & $F_{(3,9)}=6.493$ & $<0.05$ & $F_{(3,9)}=14.844$ & $<0.01$ \\
\hline Antalarmin $30 \mathrm{mg} / \mathrm{kg}+$ hypocretin-1 & $F_{(1,3)}=45.678$ & $<0.01$ & $F_{(3,9)}=6.565$ & $<0.05$ & $F_{(3,9)}=13.111$ & $<0.01$ \\
\hline Vehicle + footshock & $F_{(1,13)}=55.275$ & $<0.001$ & $F_{(2,26)}=11.874$ & $<0.001$ & $F_{(2,26)}=18.209$ & $<0.001$ \\
\hline SB334867 5 mg/kg + footshock & $F_{(1,5)}=8.331$ & $<0.05$ & $F_{(2,10)}=11.709$ & $<0.01$ & $F_{(2,10)}=4.615$ & $<0.05$ \\
\hline SB334867 10 mg/kg + footshock & $F_{(1,6)}=18.071$ & $<0.01$ & $F_{(2,12)}=13.672$ & $<0.01$ & $F_{(2,12)}=4.304$ & $<0.05$ \\
\hline Antalarmin $30 \mathrm{mg} / \mathrm{kg}+$ footshock & $F_{(1,5)}=96.425$ & $<0.001$ & $F_{(2,10)}=12.671$ & $<0.01$ & $F_{(2,10)}=26.851$ & $<0.001$ \\
\hline
\end{tabular}

Table 2. Statistical values obtained by one-way ANOVA with repeated measures in the factors hole (active vs inactive) and experimental phase (acquisition, extinction, reinstatement) for each reinstatement condition

\begin{tabular}{|c|c|c|c|c|c|}
\hline & \multicolumn{2}{|l|}{ Hole } & & \multicolumn{2}{|c|}{ Experimental phase } \\
\hline & Fvalue & $p$ value & & Fvalue & $p$ value \\
\hline \multicolumn{6}{|c|}{ Vehicle + hypocretin-1 } \\
\hline Acquisition & $F_{(1.8)}=40.981$ & $<0.001$ & Active & $F_{(3,24)}=22.582$ & $<0.001$ \\
\hline Extinction & $F_{(1,8)}=3.573$ & NS & Inactive & $F_{(3,24)}=1.854$ & NS \\
\hline Saline & $F_{(1,8)}^{(1,0)}=2.286$ & NS & & & \\
\hline Reinstatement & $F_{(1,8)}^{(1,0)}=46.952$ & $<0.001$ & & & \\
\hline \multicolumn{6}{|c|}{ SB334867 5 mg/kg + hypocretin-1 } \\
\hline Acquisition & $F_{(1,3)}=14.527$ & $<0.05$ & Active & $F_{(3,9)}=13.493$ & $<0.01$ \\
\hline Extinction & $F_{(1,3)}=0.316$ & NS & Inactive & $F_{(3,9)}=1.093$ & NS \\
\hline Saline & $F_{(1,3)}^{(1,3)}=0.231$ & NS & & & \\
\hline Reinstatement & $F_{(1,3)}^{(1,3)}=3.000$ & NS & & & \\
\hline \multicolumn{6}{|c|}{ Antalarmin $30 \mathrm{mg} / \mathrm{kg}+$ hypocretin-1 } \\
\hline Acquisition & $F_{(1,3)}=37.686$ & $<0.01$ & Active & $F_{(3,9)}=9.007$ & $<0.01$ \\
\hline Extinction & $F_{(1,3)}=7.046$ & NS & Inactive & $F_{(3,9)}=1.487$ & NS \\
\hline Saline & $F_{(1,3)}=0.648$ & NS & & & \\
\hline Reinstatement & $F_{(1,3)}=33.989$ & $<0.05$ & & & \\
\hline \multicolumn{6}{|l|}{ Vehicle + footshock } \\
\hline Acquisition & $F_{(1,13)}=69.835$ & $<0.001$ & Active & $F_{(2,26)}=20.561$ & $<0.001$ \\
\hline Extinction & $F_{(1,13)}=0.021$ & NS & Inactive & $F_{(2,26)}=4.140$ & $<0.05$ \\
\hline Reinstatement & $F_{(1,13)}=16.369$ & $<0.01$ & & & \\
\hline \multicolumn{6}{|c|}{ SB334867 $5 \mathrm{mg} / \mathrm{kg}+$ footshock } \\
\hline Acquisition & $F_{(1,5)}=24.400$ & $<0.01$ & Active & $F_{(2,10)}=12.330$ & $<0.01$ \\
\hline Extinction & $F_{(1,5)}=13.900$ & $<0.05$ & Inactive & $F_{(2,10)}=5.648$ & $<0.05$ \\
\hline Reinstatement & $F_{(1,5)}=1.327$ & NS & & & \\
\hline \multicolumn{6}{|c|}{ SB334867 $10 \mathrm{mg} / \mathrm{kg}+$ footshock } \\
\hline Acquisition & $F_{(1,6)}=18.157$ & $<0.01$ & Active & $F_{(2,12)}=9.241$ & $<0.01$ \\
\hline Extinction & $F_{(1,6)}=14.611$ & $<0.01$ & Inactive & $F_{(2,12)}=11.882$ & $<0.01$ \\
\hline Reinstatement & $F_{(1,6)}=8.392$ & $<0.05$ & & & \\
\hline \multicolumn{6}{|c|}{ Antalarmin $30 \mathrm{mg} / \mathrm{kg}+$ footshock } \\
\hline Acquisition & $F_{(1,5)}=62.701$ & $<0.01$ & Active & $F_{(2,10)}=19.355$ & $<0.001$ \\
\hline Extinction & $F_{(1,5)}^{(1,3)}=247.353$ & $<0.001$ & Inactive & $F_{(2,10)}^{(2,10)}=0.823$ & NS \\
\hline Reinstatement & $F_{(1,5)}^{(1,5)}=21.250$ & $<0.01$ & & & \\
\hline
\end{tabular}

(Peyron et al., 1998). The PVN receives Hcrt fibers from the perifornical region of the hypothalamus (Peyron et al., 1998), and a depolarization of magno- and parvocellular neurons in the PVN is induced by Hcrt-1 (Shirasaka et al., 2001; Samson et al., 2002; Follwell and Ferguson, 2002). A specific activation of CRF cells in the parvocellular division of the PVN has been also reported after Hcrt-1 administration (Sakamoto et al., 2004). Reciprocally, the application of CRF to hypothalamic slices containing Hcrt neurons increases firing rate of these cells (Winsky-Sommerer et al., 2004). This result correlates with the lack of activation of hypocretinergic neurons observed in CRF1 receptor $\mathrm{KO}$ mice in response to acute stress (Winsky-Sommerer et al., 2004). Together, these studies indicate that the Hcrt system is a key component of the pathways contributing to CRFmediated behaviors that occur in response to stressful situations (Winsky-Sommerer et al., 2005). Consistent with this notion, our data suggest that the acute anxiogenic-like effects of nicotine are related to Hcrt release in the PVN and that CRF and AVP cell stimulation is associated to this behavioral response. Indeed, we have observed an activation of Hcrt cells located in the PFA/ $\mathrm{DMH}$ following the injection of the anxiogenic dose of nicotine. Thus, PFA/DMH Hcrt neurons respond to stressful events and might activate CRF systems (Harris et al., 2005, 2007). Moreover, a high dose of nicotine has been also previously reported to increase c-Fos expression in Hcrt neurons in rats (Pasumarthi et al., 2006). On the contrary, the injection of a low dose of nicotine which induces anxiolytic-like effects did not increase c-Fos expression in Hcrt neurons. Based on our pharmacological and biochemical data and the colocalization of Hcrtr-1 with CRF and AVP neurons of the PVN reported here, Hcrtr-1 seems to be involved in the regulation of nicotine-induced anxiogenic-like effects. This location of Hcrtr-1 confirms previous results obtained in rat brain (Bäckberg et al., 2002). The role for Hcrt transmission in acute nicotine effects seems to be specific for the 
anxiogenic-like responses since the anxiolytic-like effects, hypolocomotion and antinociception induced by this drug were not modified by the previous administration of SB334867 or preprohypocretin gene deletion.

Stress exposure and other stimuli leading to nicotine relapse are crucial for the maintenance of nicotine addiction (Dravolina et al., 2007; Bilkei-Gorzo et al., 2008; Martín-García et al., 2009). We examined the ability of Hcrt-1 to induce reinstatement of previously extinguished nicotine-seeking behavior and, if so, whether the Hcrtr-1 and the CRF1 receptor were involved in this mechanism. In addition, we evaluated the role of these receptors in the reinstatement of nicotineseeking induced by stress. Intravenous nicotine-self administration was performed in freely moving naive mice that were not previously trained with any other rewarding stimulus unlike previous studies in this animal specie (Picciotto et al., 1998; Bilkei-Gorzo et al., 2008). This is an important issue since the reinforcing effects of nicotine are influenced by stress or the previous experience with food or other drugs (Thomsen and Caine, 2007), which makes the interpretation of these data difficult. Following the extinction period, the intracerebroventricular infusion of Hcrt-1 induced reinstatement of nicotineseeking and this effect was abolished by the previous administration of SB334867, suggesting a selective involvement of Hcrtr-1. In line with this finding, the intracerebroventricular and intraventral tegmental area (intra-VTA) administration of Hcrt-1 has been shown to reinstate extinguished cocaine-seeking in rats (Boutrel et al., 2005; Wang et al., 2009). The intra-VTA injection of Hcrt-1 also reinstates a previously extinguished conditioned place preference to morphine in rats (Harris et al., 2005). Interestingly, the Hcrtr-1 antagonist SB334867 was not effective to block footshock stress-induced reinstatement of nicotine-seeking in the present study. Previous studies have described that footshock stress increases CRF expression in several brain areas (Funk et al., 2006), and causes release of CRF in the VTA (Wang et al., 2005), pointing to a role for extrahypothalamic CRF in stressinduced reinstatement of drug-seeking (Shalev et al., 2009). We found that the CRF1 receptor antagonist antalarmin blocked footshock-induced reinstatement of nicotine-seeking, in agreement with earlier studies performed in rats (Zislis et al., 2007; Bruijnzeel et al., 2009). Footshock-induced CRF release in the VTA produces glutamate and dendritic dopamine release in this brain area in rats with a previous history of cocaine intake, but not in cocaine-naive rats (Wang et al., 2005). This cocaine-induced neuroadaptation in the VTA appears to play an important role in stress-induced relapse (Wang et al., 2005). Hcrt peptides have

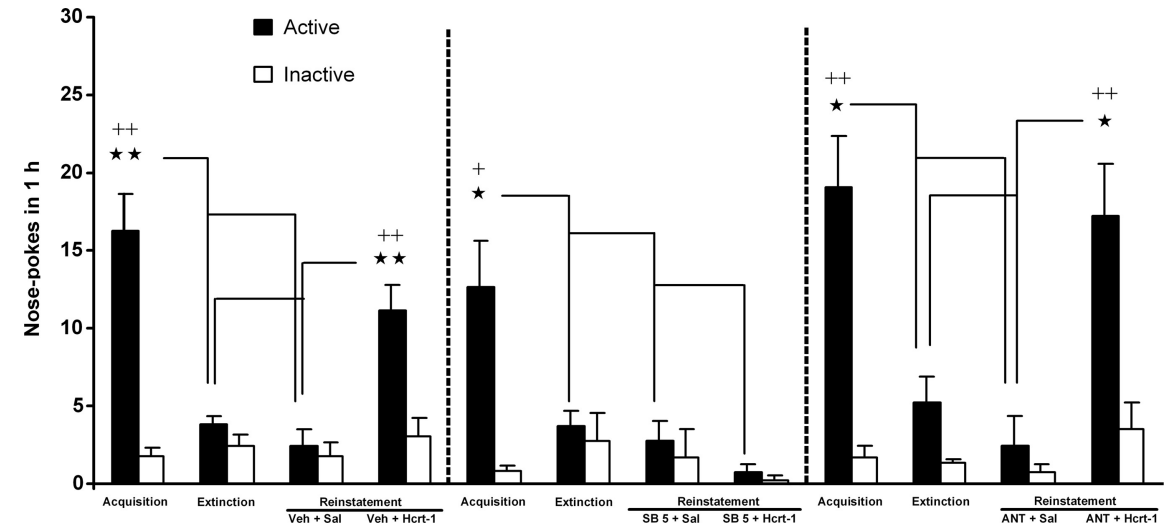

Figure 5. Hcrtr-1, but not CRF1 receptor, regulates the reinstatement of nicotine-seeking behavior induced by Hcrt-1. Mice that achieved the extinction criterion received an intracerebroventricular saline infusion preceded by $S B 334867$ (5 mg/kg, i.p.) $(n=4)$, antalarmin (30 mg/kg, s.c.) $(n=4)$, or vehicle $(n=9) 10 \mathrm{~min}$ before the reinstatement session. Next day, the same mice were $(n=4)$, or vehicle $(n=9)$ and tested for reinstatement 10 min later. SB334867 and antalarmin were administered 30 min and $1 \mathrm{~h}$, espectively, before intracerebroventricular Hcrt-1/vehicle infusions. Mean number of nose-pokes in the active $(\boldsymbol{\square})$ and inactive iteria), extinction (mean of $3 \mathrm{~d}$ criterion), and reinstatement (intracerebroventricular infusion of vehicle/Hcrt-1). ${ }^{\star} p<0.05$, 作 0.01 , differences between experimental phases when considering the active hole; ${ }^{+} p<0.05,{ }^{++} p<0.01$, differences

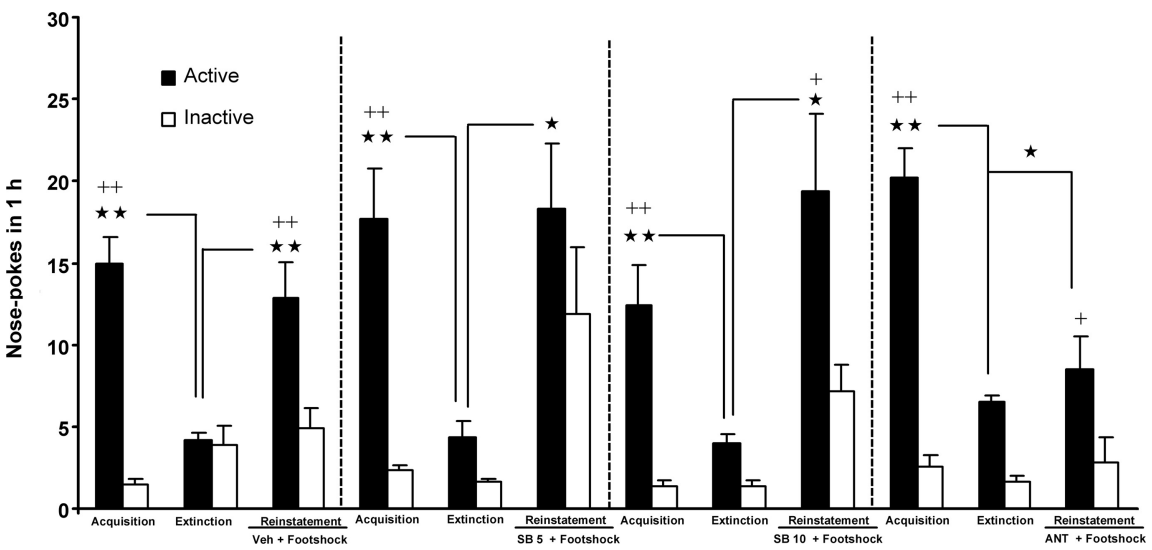

Figure 6. CRF1 receptor, but not Hcrtr-1, regulates footshock stress-induced reinstatement of nicotine-seeking behavior. Mice that achieved the extinction criterion received intermittent footshock stimuli $(0.22 \mathrm{~mA}, 5 \mathrm{~min})$ immediately before the reinstate$(30 \mathrm{mg} / \mathrm{kg}$, s.c.) $(n=6)$. SB334867 and antalarmin were administered $30 \mathrm{~min}$ and $1 \mathrm{~h}$, respectively, before electric footshock. Mean number of nose-pokes in the active $(\square)$ and inactive $(\square)$ holes during the different experimental phases: acquisition of $\mathrm{mA}$ footshock stress). ${ }^{\star} p<0.05,{ }^{\star \star} p<0.01$, differences between experimental phases when considering the active hole; ${ }^{+} p<$ $0.05,{ }^{++} p<0.01$, significant differences between holes within the same experimental phase (Newman-Keuls test).

also important effects in the VTA (Borgland et al., 2009) and Hcrt-1 signaling is involved in the formation of drug-dependent synaptic plasticity in this brain area (Borgland et al., 2006; Bonci and Borgland, 2009). A recent study has shown that the Hcrtr-1 antagonist SB408124 blocks the reinstatement of cocaineseeking, as well as glutamate and dopamine release in the VTA, induced by the intra-VTA perfusion of Hcrt-1 (Wang et al., 2009). Interestingly, footshock-induced cocaine reinstatement and associated neurotransmitter enhancement were not prevented by the intra-VTA perfusion of the Hcrtr-1 antagonist (Wang et al., 2009). Furthermore, the CRF antagonist $\alpha$-helical CRF did not modify the Hcrt-1 neurochemical and behavioral effects, while blocked similar responses induced by footshock (Wang et al., 2009). In agreement, we found that the pretreatment with the 
CRF1 receptor antagonist antalarmin at a dose that blocks footshock stress-induced reinstatement of nicotine-seeking had no effects on the reinstatement induced by Hcrt-1. Furthermore, a previous study also showed that the CRF antagonist D-Phe-CRH-12-41 attenuated, but not abolished, Hcrt-1induced reinstatement of cocaine-seeking (Boutrel et al., 2005). Therefore, it is tempting to hypothesize that, similar to the effects of cocaine, the reinstatement of nicotine-seeking induced by Hcrt- 1 and by CRF-dependent stress could be mediated by independent mechanisms leading both to similar final biochemical and behavioral changes. In contrast with this hypothesis, the systemic injection of the Hcrtr-1 antagonist SB334867 inhibits yohimbine-induced reinstatement of ethanol-seeking (Richards et al., 2008) and footshock-induced cocaine-seeking in rats (Boutrel et al., 2005), although the high dose of this antagonist used in the last study could induce nonspecific behavioral impairments such as abnormal posture and immobility (Nair et al., 2008). Future research is needed to elucidate other possible mechanisms underlying reinstatement of nicotine-seeking induced by Hcrt-1. In addition, future investigation will be also necessary to explore the potential participation of Hcrt transmission in the other two modalities involved in nicotine relapse, i.e., nicotine-associated cues and reexposure to nicotine.

In conclusion, our study suggests that Hcrt peptides play a crucial role in the modulation of the acute anxiogenic-like effects of nicotine and the neurobiological processes driving to relapse to nicotine-seeking. The modulation that Hcrt peptides exert on nicotine anxiogenic-like effects is associated to an activation of CRF and AVP neurons in the PVN. We also show that the mechanism by which Hcrt-1 induces nicotine-seeking reinstatement does not depend on CRF. Instead, CRF mediates the reinstatement of nicotine-seeking induced by stress. Therefore, we reveal that Hcrt and CRF modulate nicotine relapse through independent, but complementary mechanisms. This could have important therapeutic implications since a combination therapy of Hcrt and CRF antagonists could offer strong efficacy to avoid relapse to drug-seeking compared with a single-target approach, as recently suggested (Borgland et al., 2009). The identification of hypothalamic Hcrts as a new neuromodulatory system involved in reinstatement of nicotine-seeking could improve the therapeutic approaches leading to treat tobacco addiction since the prevention of relapse after smoking cessation is still the main need uncovered by the currently available treatments.

\section{References}

Aston-Jones G, Smith RJ, Sartor GC, Moorman DE, Massi L, Tahsili-Fahadan P, Richardson KA (2009) Lateral hypothalamic orexin/hypocretin neurons: a role in reward-seeking and addiction. Brain Res. Advance online publication. Retrieved October 7, 2009. doi:10.1016/j.brainres.2009.09.106.

Bäckberg M, Hervieu G, Wilson S, Meister B (2002) Orexin receptor-1 (OX-R1) immunoreactivity in chemically identified neurons of the hypothalamus: focus on orexin targets involved in control of food and water intake. Eur J Neurosci 15:315-328.

Balerio GN, Aso E, Berrendero F, Murtra P, Maldonado R (2004) Delta9tetrahydrocannabinol decreases somatic and motivational manifestations of nicotine withdrawal in mice. Eur J Neurosci 20:2737-2748.

Balerio GN, Aso E, Maldonado R (2005) Involvement of the opioid system in the effects induced by nicotine on anxiety-like behaviour in mice. Psychopharmacology (Berl) 181:260-269.

Berrendero F, Mendizábal V, Robledo P, Galeote L, Bilkei-Gorzo A, Zimmer A, Maldonado R (2005) Nicotine-induced antinociception, rewarding effects, and physical dependence are decreased in mice lacking the preproenkephalin gene. J Neurosci 25:1103-1112.

Bilkei-Gorzo A, Rácz I, Michel K, Darvas M, Maldonado R, Zimmer A (2008) A common genetic predisposition to stress sensitivity and stressinduced nicotine craving. Biol Psychiatry 63:164-171.
Bonci A, Borgland S (2009) Role of orexin/hypocretin and CRF in the formation of drug-dependent synaptic plasticity in the mesolimbic system. Neuropharmacology 56 (Suppl 1):107-111.

Borgland SL, Taha SA, Sarti F, Fields HL, Bonci A (2006) Orexin A in the VTA is critical for the induction of synaptic plasticity and behavioral sensitization to cocaine. Neuron 49:589-601.

Borgland, SL, Ungless MA, Bonci A (2009) Convergent actions of orexin/ hypocretin and CRF on dopamine neurons: emerging players in addiction. Brain Res. Advance online publication. Retrieved November 4, 2009. doi:10.1016/j. brainres.2009.10.068.

Boutrel B, Kenny PJ, Specio SE, Martin-Fardon R, Markou A, Koob GF, de Lecea L (2005) Role for hypocretin in mediating stress-induced reinstatement of cocaine-seeking behavior. Proc Natl Acad Sci U S A 102:19168-19173.

Bruijnzeel AW, Prado M, Isaac S (2009) Corticotropin-releasing factor-1 receptor activation mediates nicotine withdrawal-induced deficit in brain reward function and stress-induced relapse. Biol Psychiatry 66:110-117.

Chemelli RM, Willie JT, Sinton CM, Elmquist JK, Scammell T, Lee C, Richardson JA, Williams SC, Xiong Y, Kisanuki Y, Fitch TE, Nakazato M, Hammer RE, Saper CB, Yanagisawa M (1999) Narcolepsy in orexin knockout mice: molecular genetics of sleep regulation. Cell 98:437-451.

Cohen S, Lichtenstein E (1990) Perceived stress, quitting smoking, and smoking relapse. Health Psychol 9:466-478.

Cooper JO, Heron TE, Heward WL (1987) Applied behavior analysis. New York: Macmillan.

de Lecea L, Kilduff TS, Peyron C, Gao X, Foye PE, Danielson PE, Fukuhara C, Battenberg EL, Gautvik VT, Bartlett FS 2nd, Frankel WN, van den Pol AN, Bloom FE, Gautvik KM, Sutcliffe JG (1998) The hypocretins: hypothalamus-specific peptides with neuroexcitatory activity. Proc Natl Acad Sci U S A 95:322-327.

de Lecea L, Jones BE, Boutrel B, Borgland SL, Nishino S, Bubser M, DiLeone R (2006) Addiction and arousal: alternative roles of hypothalamic peptides. J Neurosci 26:10372-10375.

Dravolina OA, Zakharova ES, Shekunova EV, Zvartau EE, Danysz W, Bespalov AY (2007) mGlul receptor blockade attenuates cue- and nicotine-induced reinstatement of extinguished nicotine self-administration behavior in rats. Neuropharmacology 52:263-269.

File SE, Cheeta S, Kenny PJ (2000) Neurobiological mechanisms by which nicotine mediates different types of anxiety. Eur J Pharmacol 393:231-236.

Follwell MJ, Ferguson AV (2002) Cellular mechanisms of orexin actions on paraventricular nucleus neurones in rat hypothalamus. J Physiol 545:855-867.

Foulds J, Stapleton JA, Bell N, Swettenham J, Jarvis MJ, Russell MA (1997) Mood and physiological effects of subcutaneous nicotine in smokers and never-smokers. Drug Alcohol Depend 44:105-115.

Funk D, Li Z, Lê AD (2006) Effects of environmental and pharmacological stressors on c-fos and corticotropin-releasing factor mRNA in rat brain: relationship to the reinstatement of alcohol seeking. Neuroscience 138:235-243.

Harris GC, Aston-Jones G (2006) Arousal and reward: a dichotomy in orexin function. Trends Neurosci 29:571-577.

Harris GC, Wimmer M, Aston-Jones G (2005) A role for lateral hypothalamic orexin neurons in reward seeking. Nature 437:556-559.

Harris GC, Wimmer M, Randall-Thompson JF, Aston-Jones G (2007) Lateral hypothalamic orexin neurons are critically involved in learning to associate an environment with morphine reward. Behav Brain Res 183:43-51

Hollander JA, Lu Q, Cameron MD, Kamenecka TM, Kenny PJ (2008) Insular hypocretin transmission regulates nicotine reward. Proc Natl Acad Sci U S A 105:19480-19485.

Hsu HR, Chen TY, Chan MH, Chen HH (2007) Acute effects of nicotine on restraint stress-induced anxiety-like behavior, c-Fos expression, and corticosterone release in mice. Eur J Pharmacol 566:124-131.

Kassel JD, Unrod M (2000) Smoking, anxiety, and attention: support for the role of nicotine in attentionally mediated anxiolysis. J Abnorm Psychol 109:161-166.

Kovács KJ (2008) Measurement of immediate-early gene activation c-fos and beyond. J Neuroendocrinol 20:665-672.

Landgraf R (2005) Neuropeptides in anxiety modulation. Handb Exp Pharmacol 169:335-369.

Lawrence AJ, Cowen MS, Yang HJ, Chen F, Oldfield B (2006) The orexin system regulates alcohol-seeking in rats. Br J Pharmacol 148:752-759. 
Lightman SL (2008) The neuroendocrinology of stress: a never ending story. J Neuroendocrinol 20:880-884.

Loughlin SE, Islas MI, Cheng MY, Lee AG, Villegier AS, Leslie FM (2006) Nicotine modulation of stress-related peptide neurons. J Comp Neurol 497:575-588.

Lutfy K, Brown MC, Nerio N, Aimiuwu O, Tran B, Anghel A, Friedman TC (2006) Repeated stress alters the ability of nicotine to activate the hypothalamic-pituitary-adrenal axis. J Neurochem 99:1321-1327.

Martín-García E, Barbano MF, Galeote L, Maldonado R (2009) New operant model of nicotine-seeking behaviour in mice. Int J Neuropsychopharmacol 12:343-356.

McLellan AT, Lewis DC, O'Brien CP, Kleber HD (2000) Drug dependence, a chronic medical illness: implications for treatment, insurance, and outcomes evaluation. JAMA 284:1689-1695.

Mochizuki T, Crocker A, McCormack S, Yanagisawa M, Sakurai T, Scammell TE (2004) Behavioral state instability in orexin knock-out mice. J Neurosci 24:6291-6300.

Nair SG, Golden SA, Shaham Y (2008) Differential effects of the hypocretin 1 receptor antagonist SB334867 on high-fat food self-administration and reinstatement of food seeking in rats. Br J Pharmacol 154:406-416.

Narita M, Nagumo Y, Hashimoto S, Narita M, Khotib J, Miyatake M, Sakurai T, Yanagisawa M, Nakamachi T, Shioda S, Suzuki T (2006) Direct involvement of orexinergic systems in the activation of the mesolimbic dopamine pathway and related behaviors induced by morphine. J Neurosci 26:398-405.

Newhouse PA, Sunderland T, Narang PK, Mellow AM, Fertig JB, Lawlor BA, Murphy DL (1990) Neuroendocrine, physiologic, and behavioral responses following intravenous nicotine in nonsmoking healthy volunteers and in patients with Alzheimer's disease. Psychoneuroendocrinology 15:471-484.

Pañeda C, Huitron-Resendiz S, Frago LM, Chowen JA, Picetti R, de Lecea L, Roberts AJ (2009) Neuropeptide S reinstates cocaine-seeking behavior and increases locomotor activity through corticotrophin-releasing factor receptor 1 in mice. J Neurosci 29:4155-4161.

Parrott AC (1995) Stress modulation over the day in cigarette smokers. Addiction 90:233-244.

Pasumarthi RK, Reznikov LR, Fadel J (2006) Activation of orexin neurons by acute nicotine. Eur J Pharmacol 535:172-176.

Paxinos G, Franklin KBJ (1997) The mouse brain in stereotaxic coordinates. San Diego: Academic.

Peyron C, Tighe DK, van den Pol AN, de Lecea L, Heller HC, Sutcliffe JG, Kilduff TS (1998) Neurons containing hypocretin (orexin) project to multiple neuronal systems. J Neurosci 18:9996-10015.

Picciotto MR, Zoli M, Rimondini R, Léna C, Marubio LM, Pich EM, Fuxe K, Changeux JP (1998) Acetylcholine receptors containing the beta2 subunit are involved in the reinforcing properties of nicotine. Nature 391:173-177.

Pomerleau OF (1986) Nicotine as a psychoactive drug: anxiety and pain reduction. Psychopharmacol Bull 22:865-869.

Richards JK, Simms JA, Steensland P, Taha SA, Borgland SL, Bonci A, Bartlett SE (2008) Inhibition of orexin-1/hypocretin-1 receptors inhibits yohimbineinduced reinstatement of ethanol and sucrose seeking in Long-Evans rats. Psychopharmacology (Berl) 199:109-117.

Rodgers RJ, Halford JC, Nunes de Souza RL, Canto de Souza AL, Piper DC, Arch JR, Upton N, Porter RA, Johns A, Blundell JE (2001) SB-334867, a selective orexin-1 receptor antagonist, enhances behavioural satiety and blocks the hyperphagic effect of orexin-A in rats. Eur J Neurosci 13:1444-1452.
Sakamoto F, Yamada S, Ueta Y (2004) Centrally administered orexin-A activates corticotropin-releasing factor-containing neurons in the hypothalamic paraventricular nucleus and central amygdaloid nucleus of rats: possible involvement of central orexins on stress-activated central CRF neurons. Regul Pept 118:183-191.

Sakurai T, Amemiya A, Ishii M, Matsuzaki I, Chemelli RM, Tanaka H, Williams SC, Richardson JA, Kozlowski GP, Wilson S, Arch JR, Buckingham RE, Haynes AC, Carr SA, Annan RS, McNulty DE, Liu WS, Terrett JA, Elshourbagy NA, Bergsma DJ, et al. (1998) Orexins and orexin receptors: a family of hypothalamic neuropeptides and $\mathrm{G}$ protein-coupled receptors that regulate feeding behavior. Cell 92:573-585.

Samson WK, Taylor MM, Follwell M, Ferguson AV (2002) Orexin actions in hypothalamic paraventricular nucleus: physiological consequences and cellular correlates. Regul Pept 104:97-103.

Shalev U, Erb S, Shaham Y (2009) Role of CRF and other neuropeptides in stress-induced reinstatement of drug seeking. Brain Res. Advance online publication. Retrieved July 24, 2009. doi:10.1016/j.brainres.2009.07.028.

Sharf R, Sarhan M, DiLeone RJ (2009) Role of orexin/hypocretin in dependence and addiction. Brain Res. Advance online publication. Retrieved August 21, 2009. doi:10.1016/j.brainres.2009.08.028.

Shirasaka T, Miyahara S, Kunitake T, Jin QH, Kato K, Takasaki M, Kannan H (2001) Orexin depolarizes rat hypothalamic paraventricular nucleus neurons. Am J Physiol Regul Integr Comp Physiol 281:R1114-R1118.

Shram MJ, Funk D, Li Z, Lê AD (2007) Acute nicotine enhances c-fos mRNA expression differentially in reward-related substrates of adolescent and adult rat brain. Neurosci Lett 418:286-291.

Singewald N, Salchner P, Sharp T (2003) Induction of c-Fos expression in specific areas of the fear circuitry in rat forebrain by anxiogenic drugs. Biol Psychiatry 53:275-283.

Soria G, Mendizábal V, Touriño C, Robledo P, Ledent C, Parmentier M, Maldonado R, Valverde O (2005) Lack of CB1 cannabinoid receptor impairs cocaine self-administration. Neuropsychopharmacology 30:16701680.

Thomsen M, Caine SB (2007) Intravenous drug self-administration in mice: practical considerations. Behav Genet 37:101-118.

Valentine JD, Matta SG, Sharp BM (1996) Nicotine-induced cFos expression in the hypothalamic paraventricular nucleus is dependent on brainstem effects: correlations with cFos in catecholaminergic and noncatecholaminergic neurons in the nucleus tractus solitarius. Endocrinology 137:622-630.

Wang B, Shaham Y, Zitzman D, Azari S, Wise RA, You ZB (2005) Cocaine experience establishes control of midbrain glutamate and dopamine by corticotropin-releasing factor: a role in stress-induced relapse to drug seeking. J Neurosci 25:5389-5396.

Wang B, You ZB, Wise RA (2009) Reinstatement of cocaine seeking by hypocretin (orexin) in the ventral tegmental area: independence from the local corticotropin-releasing factor network. Biol Psychiatry 65:857-862.

Winsky-Sommerer R, Yamanaka A, Diano S, Borok E, Roberts AJ, Sakurai T, Kilduff TS, Horvath TL, de Lecea L (2004) Interaction between the corticotropin-releasing factor system and hypocretins (orexins): a novel circuit mediating stress response. J Neurosci 24:11439-11448.

Winsky-Sommerer R, Boutrel B, de Lecea L (2005) The corticotrophinreleasing factor/hypocretin circuitry. Mol Neurobiol 32:285-294.

Zislis G, Desai TV, Prado M, Shah HP, Bruijnzeel AW (2007) Effects of the CRF receptor antagonist D-Phe $\mathrm{CRF}(12-41)$ and the alpha2-adrenergic receptor agonist clonidine on stress-induced reinstatement of nicotineseeking behavior in rats. Neuropharmacology 53:958-966. 